\title{
Expressions of ion co-transporter genes in salicylate-induced tinnitus and treatment effects of spirulina
}

\author{
Juen-Haur Hwang ${ }^{1,2}$ and Yin-Ching Chan $^{3^{*}}$
}

\begin{abstract}
Background: Although the activity of tinnitus-related ion co-transporter are known, their mRNA expressions has seldom been reported. We aimed to investigate the mRNA expressions of tinnitus-related ion co-transporter genes, and treatment effects of Spirulina.

Methods: The mRNA expressions of $\mathrm{K}^{+}-\mathrm{Cl}^{-}$co-transporter (KCC2) and Na-K-2Cl co-transporter 1 (NKCC1) genes in the cochlea and brain of mice were evaluated after tinnitus was induced by intraperitoneal injection of salicylate.

The effects of spirulina water extract on these gene expressions were investigated.

Results: Compared to the control group, the tinnitus scores increased significantly, however, the salicylate-induced tinnitus could be reduced significantly by spirulina water extract. The tinnitus group had higher of borderline significance mRNA expression of KCC2 gene in the cochlear, significantly higher in the temporal lobes and in the frontal lobes. Meanwhile, compared to the tinnitus group, the spirulina group had significantly lower mRNA expression of KCC2 gene in the cochlear, temporal lobes, frontal lobes and parahippocampus/hippocampus. However, the NKCC1 mRNA expression was not significantly different between three groups in the cochlea and these brain areas.

Conclusion: Salicylate-induced tinnitus might be associated with increased mRNA expression of KCC2 gene, but not with mRNA expressions of NKCC1 gene in the cochlear and some tinnitus-related brain areas. Spirulina reduced the expression of KCC2 genes in salicylate-induced tinnitus.

Keywords: Tinnitus, Salicylate, mRNA, $\mathrm{K}^{+}-\mathrm{Cl}^{-}$co-transporter gene, Na-K-Cl co-transporter gene, Spirulina

Abbreviations: CAT, Catalase; COX-2, Cyclooxygenase type 2; CPC, C-phycocyanin; GR, $\gamma$-amino butyric acid receptor; IL-1 $\beta$, Interleukine-1 $\beta$; $\mathrm{KCC} 2, \mathrm{~K}^{+}-\mathrm{Cl}^{-}$co-transporter; $\mathrm{NADPH}$, Nicotinamide adenine dinucleotide phosphate; NKCC1, Na-K- 2Cl co-transporter 1; NR, N-methyl D-aspartate receptor; SAMP8, Senescence-accelerated prone-8; SPL, Sound pressure level; TNF-a, Tumor necrosis factor-a
\end{abstract}

\section{Background}

Subjective tinnitus is most commonly believed to originate from the cochlear and/or central nervous system dysfunction at the levels of the brainstem, subcortical and cortical level, as well as the limbic system [1,2]. The functions of certain neurotransmitter receptors, ion channels and/or co-transporters have been proposed to be associated with tinnitus, for example, activation of vanilloid receptors in the inner ear [3], N-methyl D-aspartate receptor (NMDA

\footnotetext{
* Correspondence: ycchan@pu.edu.tw

${ }^{3}$ Department of Food and Nutrition, Providence University, Taichung, Taiwan Full list of author information is available at the end of the article
}

receptor, NR) in the inner ear [4], acetylcholine receptors in the auditory cortex [5], and dopamine receptors in the auditolimbic dopaminergic pathway exhibited excitatory effects on tinnitus [6]. On the contrary, activation of cannabinoid receptors in the ventral cochlear nucleus [7] and $\gamma$-amino butyric acid receptors (GABA receptor, GR) in the inferior colliculus (IC) [8] or auditory cortex [9] exhibited inhibitory effects on tinnitus.

Some co-transporter and/or ion channels, for example, $\mathrm{K}^{+}-\mathrm{Cl}^{-}$co-transporter (KCC2) $[10,11]$, voltage-gated sodium channels [12, 13], transient outward potassium currents, the glycine-induced chloride channels [14], 
L-type calcium channels [15], and $\mathrm{Na}-\mathrm{K}-2 \mathrm{Cl}$ co-transporter 1 (NKCC1) [16], were reported to be associated with tinnitus. Among them, $\mathrm{KCC} 2$ is a neuron-specific $\mathrm{Cl}^{-}$transporter whose role in adult central nervous neurons is to maintain low intracellular $\mathrm{Cl}^{-}$concentrations needed for the hyperpolarizing responses to the inhibitory amino acid GABA and glycine of the auditory nucleus [10, 17]. The $\mathrm{NKCC}$ is a class of membrane proteins that transport $\mathrm{Na}$, $\mathrm{K}$, and $\mathrm{Cl}$ ions into and out of a wide variety of epithelial and non-epithelial cells. The NKCC1 isoform is present in a wide variety of tissues, whereas, NKCC2 is found only in the kidney [18]. Inhibition of NKCC1 with its potent antagonist bumetanide reduces pain behavior in rats following spinal cord injury [19].

Tinnitus-related changes in gene expression have also played an important role in tinnitus. For example, the mRNA expression of the c-fos gene increased in the auditory brainstem [20] and cortices [21]. The expression of NR subtype 2A (NR2A) genes increased in the auditory cortices of rats in salicylate-induced tinnitus [21]. The expression levels of NR2B, tumor necrosis factor- $\alpha$ (TNF- $\alpha)$ and interleukine-1 $\beta$ (IL-1 $\beta$ ) genes increased significantly, whereas cyclooxygenase type 2 (COX-2) gene expression decreased in the cochlea and IC of mice with salicylate-induced tinnitus [22, 23]. NKCC1 mRNA expression increased in the chronic tinnitus and the recovery period, but decreased in the phase of acute tinnitus [16]. However, the mRNA expression of $\mathrm{KCC} 2$ was still unclear in tinnitus. Furthermore, based on recent animal studies in our laboratory, neural inflammation and oxidation-reduction status (redox) may be novel mechanisms in tinnitus [22-24]. Meanwhile, it is well known that inflammation and/or oxidative stress could violate cell functions not only at the cell membrane level, but also at the cytoplasm and nucleus levels. Thus, it is reasonable to expect that antiinflammatory and/or anti-oxidative agents might prevent cell dysfunction in genetic level and beyond.

Spirulina is a microscopic blue-green alga. Spirulina platensis and its active ingredient, C-phycocyanin (CPC), exert antioxidative, anti-inflammatory effects via inhibition of COX-2 [25] and/or nicotinamide adenine dinucleotide phosphate (NADPH) oxidase enzymes [26]. S. platensis water extract significantly slowed the loss of memory by augmenting catalase (CAT) activity in the brain of the senescence- accelerated prone-8 (SAMP8) mouse sub-strain [27]. CPC and S. platensis water extract reduced salicylateinduced tinnitus and down-regulated mRNA and protein expression for NR2B, TNF- $\alpha$, IL-1 $\beta$, and COX-2 genes in the cochlea and IC of SAMP8 mice [24]. It reduced also salicylate-induced over-expression of the manganesesuperoxide dismutase (Mn-SOD) gene and malondialdehyde (MDA) levels, but increased salicylate-induced down-regulation of the CAT gene in many brain areas
[28]. However, the effects of S. platensis water extract on the mRNA expression of KCC2 and/or NKCC1 genes after salicylate-induced tinnitus have not so far been reported.

As we have mentioned above, the functions of $\mathrm{KCC} 2$ and NKCC1 were associated with tinnitus. But, the mRNA expression of these co-transporter genes in salicylateinduced tinnitus and the effects of S. platensis water extract on them were still limited or unclear. Therefore, we aimed to investigate these questions. We hypothesized that mRNA expression of KCC2 and/or NKCC1 genes altered after 4-days of salicylate-induced tinnitus in the cochlea and brain. S. platensis water extract could modulate on the expression of $\mathrm{KCC} 2$ and/or NKCC1 genes after salicylate-induced tinnitus.

\section{Methods \\ Animals}

Twenty-four 3-month-old male SAMP8 mice were randomly and equally divided into three groups (8 mice in each group): a control group (saline-treated), tinnitus group (salicylate-treated), and spirulina group (salicylate plus S. platensis water extract-treated). All groups were fed with normal diet. Institutional Animal Care and Use Committee of Dalin Tzu Chi Hospital approved the protocol used in this study.

\section{Behavioral conditioning to active avoidance task}

All mice were trained to perform an active avoidance task, which was performed in a conditioning box with an electrical floor and a climbing pole, according to the design of Guitton et al. [29] and Hwang et al. [22-24].

The conditioning paradigm consisted of six sessions performed per day for five days (day 1-5). Each session lasted 15 to $20 \mathrm{~min}$, as there were 10 trials per session. Inter-trial intervals lasted at least one minute. For each trial, the conditioning stimulus was a $50 \mathrm{~dB}$ sound pressure level (SPL) pure tone with a frequency of $10 \mathrm{kHz}$ and of a three-second duration, and the unconditioned stimulus was a $3.7 \mathrm{~mA}$ electric foot-shock presented for $30 \mathrm{~s}$, re. Guitton's protocol [29], by adjusting the electric voltage with fixed copper wire resistance on the floor. The time between the conditioned stimulus and the unconditioned stimulus was one second. The mice would climb up through the pole into a safe area after the coupled conditioned and unconditioned stimuli. Electrical shocks were stopped by the experimenter when the animal climbed correctly. The "true-positive" score was the level of performance assessed by the number of times the mice climbed correctly in response to sound. Mice were considered to be conditioned when the "true-positive" score reached at least $80 \%$ in three consecutive sessions. Only conditioned mice were placed in the tinnitus experiments. 


\section{Induction and testing of tinnitus}

When conditioned, an active avoidance task of one session with 10 trials was performed $2.0 \mathrm{~h}$ after intraperitoneal injections of saline, either alone or containing $300 \mathrm{mg} / \mathrm{kg}$ sodium salicylate (Sigma - Aldrich, St. Louis, MO) for 4 days (day $6 \sim 9$ ). To avoid changes attributable to hearing loss induced by salicylate (about 10 to $20 \mathrm{~dB}$ during 4-days injections), the intensity of the sound that elicited the behavioral responses was adjusted by increasing the sound intensity to $70 \mathrm{~dB}$ SPL for the salicylate-treated group. By doing so, we could keep the sound sensation levels of all mice in three groups almost similar [22-24].

During tinnitus testing, a sound of three-seconds duration was given first for $3.0 \mathrm{~s}$ in each trial, and the mice were observed for another $5.0 \mathrm{~s}$ to check if they would perform the task correctly (true-positive). If so (true-positive), the mice were put down on the floor for ongoing observation, i.e., if animals stayed on the safe area $>10$ s. If not, electrical shock was given by the experimenter to remind the mice to climb up the pole. Then, the mice were also placed on the floor for ongoing observation, i.e., if animals stayed on the safe area $>10 \mathrm{~s}$.

Finally, the experimenter observed the total number (false-positive score or tinnitus score) of times the mice climbed during the inter-trial silent period of $1.0 \mathrm{~min}$ composed of 10 trials.

\section{Samples isolation and RNA extraction from the cochlea and brain}

The pairs of cochlea, brainstem including the IC, temporal lobes, frontal lobes, and para-hippocampus/ hippocampus were immediately dissected using a Zeiss stereomicroscope and stored at $-80{ }^{\circ} \mathrm{C}$ refrigerator until used. RNA isolation was performed using the RNA-Bee isolation reagent (Friendswood, USA) with a tissue homogenizer according to the manufacturer's protocol. The RNA quality was assessed by an Agilent Bioanalyzer 2100 , and the ratio of absorbance measurements was conducted at 260 and $280 \mathrm{~nm}$ using the nanodrop method.

\section{Reverse transcription-polymerase chain reaction (RT-PCR)} cDNA was synthesized from total RNA by reverse transcription using MMLV high performance reverse transcriptase (Epicentre Biotechnologies, USA) in a $\mathrm{P} \times 2$ Thermal cycler (Thermo Electron Corporation Bioscience Technologies Division, USA). For each RT reaction, a positive control was performed with $1.0 \mu \mathrm{g}$ of total RNA. RT was carried out at $37{ }^{\circ} \mathrm{C}$ for $1 \mathrm{~h}$. For PCR amplification, $3.0 \mu \mathrm{L} \mathrm{cDNA}$ and primers were used according to the supplier's instructions with DreamTaq ${ }^{\text {Tix }}$ DNA polymerase (Fermentase, USA). The primers were: $\mathrm{KCC} 2-\mathrm{F}-5^{\prime}-\mathrm{CTC}$ AAC AACCTGACGGACTG-3', KCC2-R-5'-GCACAA CACCATTGGTTGCG-3' for brain tissues [30]; KCC2-F-
5'-ATGTACATCCTTGGCACGAT -3', KCC2-R-5'-AGG AAGACC AAGGCAAACTT-3' for cochlear tissues [31]; NKCC1-F-5'-TGT TGGATTCGC AGAGACTG-3', NKC C1-R-5' -GTTCCTTTGGGTATGGCTGA-3' [32]; $\beta$-actin F-5'-CCACACCCGCCACCAGTTCG-3', $\beta$-actin R-5' CCCATTCCC ACCATC ACACC-3' [33]. The thermal cycling conditions for PCR were adjusted to the following: $3.0 \mathrm{~min}$ initial set-up at $95^{\circ} \mathrm{C}$; followed by 50 cycles, each of which consisted of $45 \mathrm{~s}$ of denaturation at $95^{\circ} \mathrm{C}, 45 \mathrm{~s}$ of annealing at $56{ }^{\circ} \mathrm{C}$, and $72 \mathrm{~s}$ of extension at $72{ }^{\circ} \mathrm{C}$ for KCC2 gene of brain tissues; $45 \mathrm{~s}$ of denaturation at $95{ }^{\circ} \mathrm{C}$, $45 \mathrm{~s}$ of annealing at $50{ }^{\circ} \mathrm{C}$, and $72 \mathrm{~s}$ of extension at $72{ }^{\circ} \mathrm{C}$ for KCC2 gene of cochlear tissues; of $45 \mathrm{~s}$ of denaturation at $95^{\circ} \mathrm{C}, 45 \mathrm{~s}$ of annealing at $52.1{ }^{\circ} \mathrm{C}$, and $72 \mathrm{~s}$ of extension at $72{ }^{\circ} \mathrm{C}$ for NKCC1 gene; of $45 \mathrm{~s}$ of denaturation at $95{ }^{\circ} \mathrm{C}$, $45 \mathrm{~s}$ of annealing at $50{ }^{\circ} \mathrm{C}$, and $72 \mathrm{~s}$ of extension at $72{ }^{\circ} \mathrm{C}$ for $\beta$-actin gene. A final $10 \mathrm{~min}$ at $72{ }^{\circ} \mathrm{C}$ for all above genes.

\section{Quantitation of PCR products}

The DNA products were measured by the Mini Horizontal Electrophoresis System (MJ-105/MP-100, Major Science, Taiwan) and by E-Box-1000/26 M Inspection Certificate \& Analysis Systems (E-Box Spp-010 E-capt soft ware, USA). The expression levels of $\mathrm{KCC} 2$ and $\mathrm{NKCC} 1$ genes were presented as relative ratios in comparison to $\beta$-actin gene.

\section{Statistical analysis}

The data are presented as the mean \pm standard deviation (SD), unless indicated otherwise. The tinnitus scores were compared between the three groups by a one-way ANOVA test. The mRNA expression levels of KCC2, NKCC1 or $\beta$-actin genes at each site were compared also by one-way ANOVA test. All above analysis were performed by the commercialized software "STATA10", and $p$ values $<0.05$ were considered statistically significant.

\section{Results}

Figure 1 display the tinnitus scores before, and 4.0 days after salicylate injection. The tinnitus score was not significantly different in three groups before intraperitoneal salicylate injection $(4.3 \pm 2.9$ versus $3.8 \pm 2.9$ versus $2.0 \pm 1.0, p=0.3318)$. But, the tinnitus score was significantly different in three groups four days after intraperitoneal salicylate injection $(7.6 \pm 3.8$ versus $14.5 \pm 4.6$ versus $5.4 \pm 3.4, p=0.0005)$. The tinnitus group had a higher significant tinnitus score than the control group $(p=0.006)$; whereas the spirulina group had significantly lower tinnitus score than the tinnitus group $(p=0.001)$.

Figure 2 shows the mRNA expression levels of the KCC2 gene in the cochlea and several brain areas. The KCC2 mRNA expression was significantly different between three groups in the cochlea (one-way ANOVA, $p=0.0036$ ). The tinnitus group had higher of borderline 


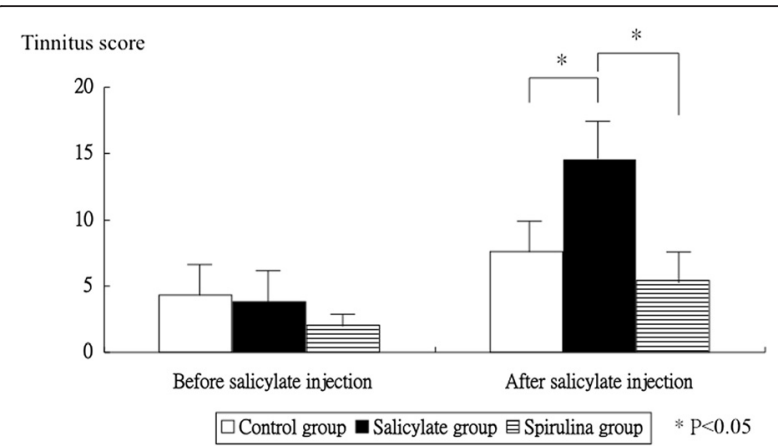

Fig. 1 The tinnitus scores before and after salicylate injection. The tinnitus score was not significantly different in three groups before salicylate injection. However, after salicylate injection, the tinnitus group had higher significantly tinnitus score than the control group, and the spirulina group had significantly lower tinnitus score than the tinnitus group

significance mRNA expression of KCC2 gene than the control group in the cochlea $(1.96 \pm 0.22$ versus $1.72 \pm 0.13$, $p=0.066)$; whereas the spirulina group had significantly lower mRNA expression of KCC2 gene than the tinnitus group in the cochlea $(1.58 \pm 0.12$ versus $1.96 \pm 0.22$, $p=0.003)$. Second, the KCC 2 mRNA expression was different and of borderline significance between the three groups in the brainstem $(2.34 \pm 0.28$ versus $2.36 \pm 0.43$ versus $1.94 \pm 0.30$, one-way ANOVA, $p=0.0937)$. Third, the KCC2 mRNA expression was significantly different between the three groups in the temporal lobes (one-way ANOVA, $p=0.0067)$. The tinnitus group had significantly higher mRNA expression of KCC2 gene than the control group in the temporal lobes $(0.82 \pm 0.24$ versus $0.42 \pm 0.19$, $p=0.025$ ), and the spirulina group had significantly lower mRNA expression of KCC2 gene than the tinnitus group in the temporal lobes $(0.37 \pm 0.25$ versus $0.82 \pm 0.24$, $p=0.010)$. Fourth, the KCC2 mRNA expression was

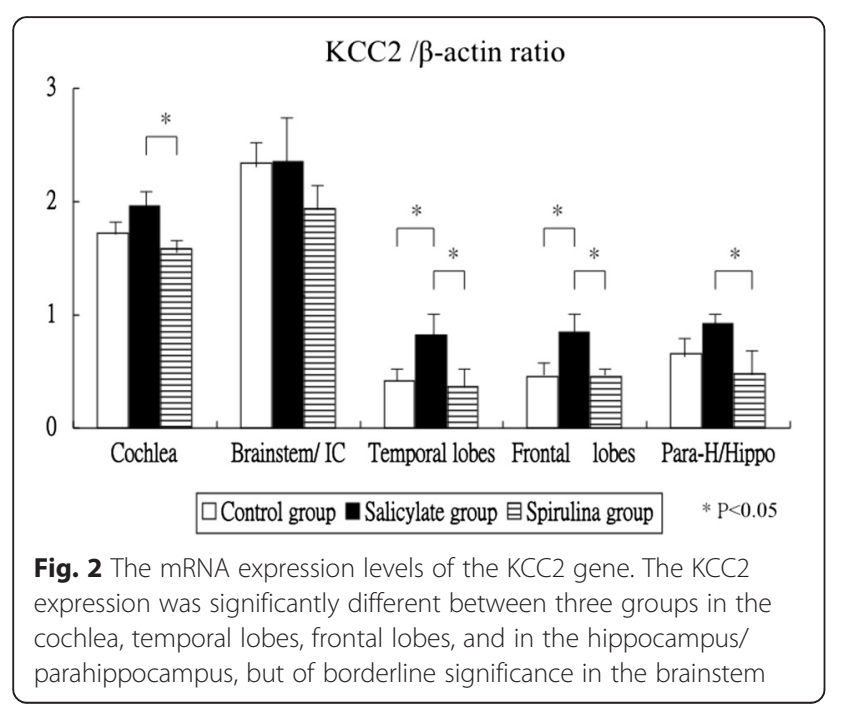

significantly different between three groups in the frontal lobes (one-way ANOVA, $p=0.0008$ ). The tinnitus group had significantly higher mRNA expression of KCC2 gene than the control group in the frontal lobes $(0.85 \pm 0.23$ versus $0.46 \pm 0.12, p=0.003$ ), and the spirulina group had significantly lower mRNA expression of $\mathrm{KCC} 2$ gene than the tinnitus group in the temporal lobes $(0.45 \pm 0.11$ versus $0.85 \pm 0.23, p=0.002)$. Fifth, the KCC2 mRNA expression was significantly different between three groups in the para-hippocampus/hippocampus (one-way ANOVA, $p=0.0074)$. The tinnitus group did not display significantly higher mRNA expression of KCC2 gene than the control group in the hippocampus/parahippocampus $(0.92 \pm 0.11$ versus $0.66 \pm 0.23, p=0.143)$, but the spirulina group had significantly lower mRNA expression of KCC2 gene than the tinnitus group in the parahippocampus/ hippocampus $(0.48 \pm 0.25$ versus $0.92 \pm 0.11, p=0.006)$.

Figure 3 shows the mRNA expression levels of the NKCC1 gene in the cochlea and several brain areas. The NKCC1 mRNA expression was not significantly different between the three groups of the cochlea $(1.70 \pm 0.89$ versus $1.45 \pm 0.60$ versus $1.08 \pm 0.64$, one-way ANOVA, $p=0.3469)$, in the brainstem (2.26 \pm 0.82 versus $2.66 \pm 0.20$ versus $2.80 \pm 0.80$, one-way ANOVA, $p=0.3714$ ), in the temporal lobes $(1.75 \pm 0.23$ versus $1.78 \pm 0.19$ versus $1.94 \pm 0.12$, one-way ANOVA, $p=0.1991$ ), in the frontal lobes $(0.78 \pm 0.20$ versus $0.78 \pm 0.17$ versus $0.68 \pm 0.15$, one-way ANOVA, $p=0.5237)$, and in the parahippocampus/hippocampus $(1.13 \pm 0.61$ versus $0.87 \pm 0.32$ versus $0.95 \pm 0.30$, one-way ANOVA, $p=0.5802$ ).

\section{Discussion}

This experimental study showed that mRNA expression of KCC2 gene increased, whereas NKCC1 gene expression did not change significantly, in the cochlea and several tinnitus-related brain areas during salicylate-induced tinnitus. Combined with previous reports about the changes of ion channel and/or co-transporter functions

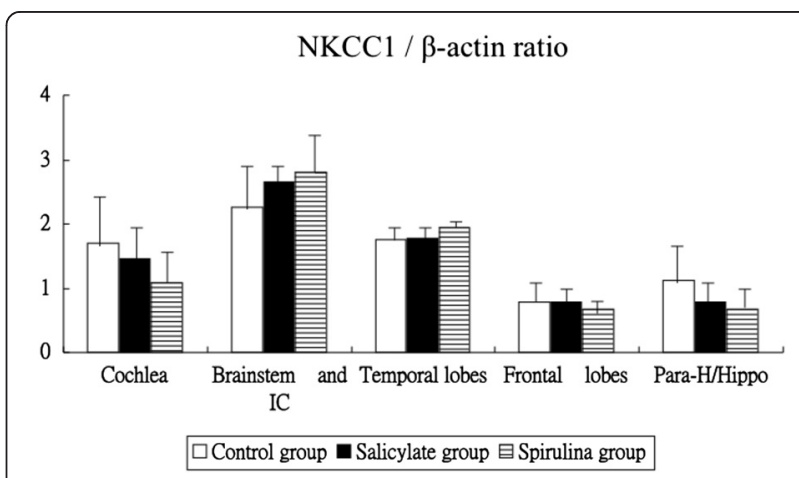

Fig. 3 The mRNA expression levels of the NKCC1 gene. The KCC2 expression was not significantly different between three groups in all tested areas 
$[10,11,18,19]$, we suggested that a high dose of salicylate could not only induce tinnitus, but also could modulate expressions of $\mathrm{KCC} 2$ in the genetic level and beyond in mice. However, our results related to NKCC1 gene expression were not consistent with findings of Yao et al. [16], in which the NKCC1 mRNA expression increased in the chronic tinnitus phase and the recovery period, but decreased in the acute tinnitus phase.

Early expression of the KCC2 selectively enhances GABAergic synapses [34]. Targeted deletion of the neuronal-specific KCC2 generates mice with a profound seizure disorder and confirms the central role of this transporter in modulating neuronal excitability [35], whereas the $\mathrm{KCC} 2$ could promote GABAergic excitation in the mature rat hippocampus during ictal epileptiform activity [11]. K-Cl co-transporter KCC3 may be involved in degenerative peripheral neuropathies [19]. The neuronal KCC2 maintains the low intracellular chloride concentration required for the fast hyperpolarizing actions of inhibitory neurotransmitters in the mature central nervous system $(\mathrm{CNS})[10,17]$. We found that salicylate could increase the mRNA expression of KCC2. However, the exact mechanisms linking this finding and salicylateinduced tinnitus remain further studies.

The renal-specific $\mathrm{Na}-\mathrm{Cl}$ co-transporter (NCC) and $\mathrm{Na}-\mathrm{K}-2 \mathrm{Cl}$ co-transporter (NKCC2) are involved in Gitelman and Bartter syndrome, respectively, and the autosomal recessive forms of metabolic alkalosis. NKCC1 is involved in hearing, salivation, pain perception, spermatogenesis, and the control of extracellular fluid volume. Inhibition of NKCC1 with its potent antagonist bumetanide reduces pain behavior in rats following spinal cord injury [19]. NKCC1 mRNA expression increased in the chronic tinnitus and recovery period, but decreased in the acute tinnitus condition [16]. However, the expressions of NKCC1 gene were not altered significantly in the cochlea and several tinnitus-related brain areas investigated in our study. This discrepancy might be due to the differences in study design, dose of salicylate, interval between the entry and the end of study, etc.

The inflammation and/or redox imbalance might interfere with the neural cell functions via modulation of ion channels, cotransporters, and/or neurotransmitters. In addition, inflammation might alter mRNA expression of cation chloride co-transporters, including KCC2 and $\mathrm{NKCC1}$, in sensory neurons [36-38]. In acute arthritis, both NKCC1 and KCC2 mRNA increased in superficial dorsal horn, and this was accompanied by an increase in protein expression. In chronic arthritis, NKCC1 expression remained raised, but $\mathrm{KCC} 2 \mathrm{mRNA}$ and protein expression returned to control levels [36]. Furthermore, based on results from recent animal studies in our laboratory, neural inflammation [22, 23] and oxidative stress [24] may be novel mechanisms in tinnitus. We had found that spirulina water extract, with its antinflammatory and anti-oxidative abilities [25, 26], could reduce salicylate-induced tinnitus and up-regulation of TNF-alpha, IL-1beta, NR2B, and COX-2 [22, 23]. In this study, we found that spirulina could reduce the salicylateinduced up-regulation of $\mathrm{KCC} 2$ gene in the cochlea, temporal lobes, frontal lobes, and para-hippocampus/ hippocampus. Thus, we proposed that spirulina might modulate the mRNA expression of $\mathrm{KCC} 2$ by reducing neuroinflammation and/or oxidative stress. However, we indeed could not know clearly if the effect of Spirulina was to antagonize the effect of salicylate and/or was on the basal expression of these transporters.

\section{Conclusion}

Salicylate-induced tinnitus might be associated with increased mRNA expression of KCC2 gene, but not with mRNA expression of NKCC1 gene in the cochlea and tinnitus-related brain areas. This animal study provided new information that high doses of salicylate could not only induce tinnitus, but also could modulate expressions of KCC2 and NKCC1 at the genetic level and beyond in mice. In addition, spirulina water extract might modulate the mRNA expression of $\mathrm{KCC} 2$ possibly by reducing neuroinflammation and/or oxidative stress.

\section{Funding}

This study was supported in part by grants from the National Science Council, Taiwan (NSC-97-2313-B-126-004-MY3; NSC-99-2314-B-303-001-MY3).

\section{Availability of data materials}

The raw data generated/analysed during this study can be acquired by contacting with the corresponding author by e-mail.

\section{Authors' contributions}

$\mathrm{JHH}$ : designed the study, conducted analyses, performed interpretation of data, and wrote the first draft of the manuscript. YCC: assisted the design of the study and revised the intellectual content. Both authors have read and approved the final manuscript.

Competing interests

The authors declare that they have no competing interests.

Consent for publication

Not applicable.

Ethics approval and consent to participate

Institutional Animal Care and Use Committee of Dalin Tzu Chi Hospital approved the protocol used in this study.

\section{Author details}

${ }^{1}$ Department of Otolaryngology, Dalin Tzu Chi Hospital, Buddhist Tzu Chi Medical Foundation, Chiayi, Taiwan. ${ }^{2}$ School of Medicine, Tzu Chi University, Hualien, Taiwan. ${ }^{3}$ Department of Food and Nutrition, Providence University, Taichung, Taiwan.

Received: 1 April 2016 Accepted: 26 August 2016

Published online: 02 September 2016

\section{References}

1. Knipper M, Zimmermann U, Muller M. Molecular aspects of tinnitus. Hear Res. 2009;266:60-9. 
2. Issa M, Bisconti S, Kovelman I, Kileny P, Basura GJ. Human auditory and adjacent nonauditory cerebral cortices are hypermetabolic in tinnitus as measured by functional near-infrared spectroscopy (fNIRS). Neural Plast. 2016;2016:7453149.

3. Balaban CD, Zhou J, Li HS. Type 1 vanilloid expression of mammalian inner ear ganglion cells. Hear Res. 2003;175:165-70.

4. Puel JL, Guitton MJ. Salicylate-induced tinnitus: molecular mechanisms and modulation by anxiety. Prog Brain Res. 2007;166:141-6.

5. Wallhäusser-Franke E, Cuautle-Heck B, Wenz G, Langner G, Mahlke C. Scopolamine attenuates tinnitus-related plasticity in the auditory cortex. Neuroreport. 2006;17(14):1487-91.

6. Lopez-Gonzalez MA, Santiago AM, Esteban-Ortega F. Sulpiride and melatonin decrease tinnitus perception modulating the auditolimbic dopaminergic pathway. J Otolaryngol. 2007;36(4):213-9.

7. Zheng Y, Baek JH, Smith PF, Darlington CL. Cannabinoid receptor downregulation in the ventral cochlear nucleus in a salicylate model of tinnitus. Hear Res. 2007;228(1-2):105-11.

8. Bauer CA, Brozoski TJ, Holder TM, Caspary DM. Effects of chronic salicylate on GABAergic activity in rat inferior colliculus. Hear Res. 2000;147(1-2):175-82.

9. Wang HT, Luo B, Zhou KQ, Xu TL, Chen L. Sodium salicylate reduces inhibitory postsynaptic currents in neurons of rat auditory cortex. Hear Res. 2006;215(1-2):77-83.

10. Vale C, Caminos E, Martinez-Galán JR, Juiz JM. Expression and developmental regulation of the $\mathrm{K}+-\mathrm{Cl}$ - cotransporter $\mathrm{KCC} 2$ in the cochlear nucleus. Hear Res. 2005;206(1-2):107-15.

11. Viitanen T, Ruusuvuori E, Kaila K, Voipio J. The $\mathrm{K}^{+}-\mathrm{Cl}^{-}$cotransporter KCC2 promotes GABAergic excitation in the mature rat hippocampus. J Physiol. 2010;588(Pt 9):1527-40.

12. Liu Y, Li X. Effects of salicylate on voltage-gated sodium channels in rat inferior colliculus neurons. Hear Res. 2004;193:68-74.

13. Trellakis S, Lautermann J, Lehnerdt G. Lidocaine: neurobiological targets and effects on the auditory system. Prog Brain Res. 2007;166:303-22.

14. Yu M, Chen L. Modulation of major voltage- and ligand-gated ion channels in cultured neurons of the rat inferior colliculus by lidocaine. Acta Pharmacol Sin. 2008;29(12):1409-18.

15. Liu Y, Li X, Ma C, Liu J, Lu H. Salicylate blocks L-type calcium channels in rat inferior colliculus neurons. Hearing Res. 2005;205:271-6.

16. Yao $K$, Huang $Z$, Yang $K$, Huang J. The influence of sodium salicylate on the expression of $\mathrm{Na}^{+}-\mathrm{K}^{+}-2 \mathrm{Cl}^{-}$. J Audiol Speech Pathol. 2009;17:258-60.

17. Markkanen M, Karhunen T, Lano O, Ludwig A, Rivera C, Uvarov P, Airaksinen MS. Distribution of neuronal KCC2a and KCC2b isoforms in mouse CNS. J Comp Neurol. 2014;522(8):1897-914.

18. Haas M, Forbush 3rd B. The Na-K-Cl cotransporters. J Bioenerg Biomembr. 1998;30(2):161-72.

19. Hasbargen T, Ahmed MM, Miranpuri G, Li L, Kahle KT, Resnick D, Sun D. Role of NKCC1 and KCC2 in the development of chronic neuropathic pain following spinal cord injury. Ann NY Acad Sci. 2010;1198:168-72.

20. Wallhausser-Franke E. Salicylate evokes c-fos expression in the brain stem: implications for tinnitus. Neuroreport. 1997;8:725-8.

21. Jia MH, Qin ZB. Expression of c-fos and NR2A in auditory cortex of rats experienced tinnitus. Zhonghua Er Bi Yan Hou Tiu Jing Wai Ke Za Zhi. 2006:41:451-4 [Article in Chinese].

22. Hwang JH, Chen JC, Yang SY, Wang MF, Chan YC. Expression of TNF-alpha and IL-1beta genes in the cochlea and midbrain in salicylate-induced tinnitus. J Neuroinflamm. 2011;8:30-6.

23. Hwang JH, Chen JC, Yang SY, Wang MF, Liu TC, Chan YC. Expression of COX- and NMDA receptor genes at the cochlea and midbrain in salicylate-induced tinnitus. Laryngoscope. 2011;121:361-4.

24. Hwang JH, Chen JC, Chan YC. Effects of c-phycocyanin and spirulina on salicylate-induced tinnitus, expression of NMDA receptor and inflammatory genes. PLoS One. 2013:8(3):e58215.

25. Romay C, Ledón N, González R. Phycocyanin extract reduces leukotriene B4 levels in arachidonic acid-induced mouse-ear inflammation test. J Pharm Pharmacol. 1999:51:641-2.

26. McCarty MF, Barroso-Aranda J, Contreras F. Oral phycocyanobilin may diminish the pathogenicity of activated brain microglia in neurodegenerative disorders. Med Hypotheses. 2010;74:601-5.

27. Hwang JH, Lee IT, Jeng KC, Wang MF, Hou RC, Wu SM, Chan YC. Spirulina prevents memory dysfunction, reduces oxidative stress damage and augments antioxidant activity in senescence-accelerated mice. J Nutr Sci Vitaminol (Tokyo). 2011;57:186-91.
28. Hwang JH, Chang NC, Chen JC, Chan YC. Expression of antioxidant genes in the mouse cochlea and brain in salicylate-induced tinnitus and effect of treatment with spirulina platensis water extract. Audiol Neurotol. 2015:20(5):322-9.

29. Guitton MJ, Caston J, Ruel J, Johnson RM, Pujol R, Puel JL. Salicylate induces tinnitus through activation of cochlear NMDA receptors. J Neurosci. 2003;23:3944-52.

30. Pozas E, Paco S, Soriano E, Aguado F. Cajal-Retzius cells falil to trigger the developmental expression of the Cl-extruding co-transporter KCC2. Brain Res. 2008;1239:85-91.

31. Ringel F, Plesnila N. Expression and functional role of potassium-chloride cotransporters (KCC) in astrocytes and C6 glioma cells. Neurosci Lett. 2008:442(3):219-23.

32. Galen A, Cervero F. Painful stimuli induce in vivo phosphorylation and membrane mobilization of mouse spinal cord NKCC1 co-transporter. Neuroscience. 2005;133(1):245-52.

33. Tha KK, Okuma Y, Miyazaki H, Murayama T, Uehara T, Hatakeyama R, Hayashi Y, Nomura Y. Changes in expressions of proinflammatory cytokines IL-1beta, TNF-alpha and IL-6 in the brain of senescence accelerated mouse (SAM) P8. Brain Res. 2000;885(1):25-31.

34. Chudotvorova I, Ivanov A, Rama S, Hübner CA, Pellegrino C, Ben-Ari Y, Medina I. Early expression of KCC2 in rat hippocampal cultures augments expression of functional GABA synapses. J Physiol. 2005;566:671-9.

35. Delpire E, Mount DB. Human and murine phenotypes associated with defects in cation-chloride cotransport. Annu Rev Physiol. 2002;64:803-43.

36. Morales-Aza BM, Chillingworth NL, Payne JA, Donaldson LF. Inflammation alters cation chloride cotransporter expression in sensory neurons. Neurobiol Dis. 2004;17(1):62-9.

37. Topper JN, Wasserman SM, Anderson KR, Cai J, Falb D, Gimbrone Jr MA. Expression of the bumetanide-sensitive Na-K-Cl cotransporter BSC2 is differentially regulated by fluid mechanical and inflammatory cytokine stimuli in vascular endothelium. J Clin Invest. 1997;99(12):2941-9.

38. Jayakumar AR, Panickar KS, Curtis KM, Tong XY, Moriyama M, Norenberg MD $\mathrm{Na}-\mathrm{K}-\mathrm{Cl}$ cotransporter-1 in the mechanism of cell swelling in cultured astrocytes after fluid percussion injury. J Neurochem. 2011;117(3):437-48.

\section{Submit your next manuscript to BioMed Central and we will help you at every step:}

- We accept pre-submission inquiries

- Our selector tool helps you to find the most relevant journal

- We provide round the clock customer support

- Convenient online submission

- Thorough peer review

- Inclusion in PubMed and all major indexing services

- Maximum visibility for your research

Submit your manuscript at www.biomedcentral.com/submit
C Biomed Central 